\title{
Pengaruh Kualitas Layanan terhadap Kepuasan Mahasiswa dan Loyalitas Mahasiswa di Sekolah Tinggi Teknologi Jawa Barat
}

\author{
Iwan Juandi \\ Sekolah Tinggi Teknologi Jawa Barat
}

\begin{abstract}
Development of Higher Education especially in Region Kopertis IV Jabar and Banten very rapidly so competition between universities is very tight. The more intense competition between universities, the higher education services should be more optimal so that the college won the competition. The aim of this research is to know the influence of the quality of the servants and the loyalty of students of West Java High School of Technology (STT Jabar in Bandung, West Java). Respondents in this research were students of High School Technology West Java (in Bandung, of West Java Highschool of Technology academic years 2014 / 2015). The sample of this study did not distinguish all the majors, gender, area and religion the number of respondents in this study determined 46 respondents from the total number of students 84 by using sampling technique Sampling used in the form of simple random sampling method (simple random sampling). This research uses Path analysis and using help SPSS software program (Statistical Package For The Social). The results of this research there are indicate that: 1) the quality of service has a positive and significant effect on student satisfaction, 0.017 Signification is smaller than the 0.05 significance of $t$ count 2,470 which states that ho rejected which means there is influence kualiats service to satisfaction. 2) satisfaction significantly influence loyalty student, 0.583 Significantly bigger than the 0.05 significance for $\mathrm{t}$ arithmetic 0,554 which states that ho received means that there is no influence between satisfaction with royalitas. 3) the quality of service has a positive and significant influence to student loyalty. It is suggested to the next researcher to extend the scope of the research to not only one type. STT Jabar should evaluate and improve service quality.
\end{abstract}

Keywords : Quality of Service, Satisfaction, Loyalty of Customer

\begin{abstract}
Abstrak. Perkembangan Perguruan Tinggi khususnya di Di Wilayah Kopertis IV Jabar dan Banten sangat pesat sehingga persaingan antar perguruan tinggi sangat ketat Semakin ketat persaingan antar perguruan tinggi, maka pelayanan yang perguruan tinggi berikan harus lebih optimal sehingga perguruan tinggi mampu memenangkan persaingan. Tujuan dari penelitian ini adalah untuk mengetahui pengaruh kualitas pelayanan terhadap kepuasan dan loyalitas mahasiswa Sekolah Tinggi Teknologi Jawa Barat (STT Jabar di Bandung, Jawa Barat. Responden dalam penelitian ini adalah mahasisiswa Sekolah Tinggi Teknologi Jawa Barat (STT Jabar di Bandung, Jawa Barat pada angkatan 2014/2015. Sampel penelitian ini tidak membedakan semua jurusan, jenis kelamin, daerah dan agama jumlah responden dalam penelitian ini ditetapkan 46 responden dari total jumlah mahasiswa 84 dengan menggunakan teknik pengambilan sampel Penarikan sampel yang digunakan berupa metode sampling acak sederhana (simple random sampling). Penelitian ini menggunakan analisis Jalur (Path Analysis) dan menggunakan bantuan software/program SPSS (Statistical Package For The Social). Hasil penelitian ini menunjukkan bahwa: 1) kualitas pelayanan berpengaruh positif dan signifikan terhadap kepuasan mahasiswa, Signifikasi 0,017 lebih kecil dari signifikasi 0,05 sebesar $t$ hitung 2,470 yang menyatakan bahwa ho ditolak yang berarti terdapat pengaruh kualiats layanan terhadap kepuasan. 2) kepuasan berpengaruh signifikan terhadap loyalitas mahasiswa, Signifikasi 0,583 lebih lebih besar dari signifikasi 0,05 sebesar t hitung 0,554 yang menyatakan bahwa ho di terima yang berarti tidak terdapat pengaruh antara kepuasan terhadap royalitas3) kualitas pelayanan berpengaruh positif dan signifikan terhadap loyalitas mahasiswa. Disarankan kepada peneliti selanjutnya untuk memperluas ruang lingkup penelitian tidak hanya pada satu jenis. STT Jabar sebaiknya melakukan evaluasi dan meningkatkan kualitas pelayanan.
\end{abstract}

Kata kunci : Kualitas Pelayanan, Kepuasan, Loyalitas Nasabah

\section{A. PENDAHULUAN}

\section{Latar Belakang Masalah}

Semakin meningkatnya jumlah Perguruan Tinggi Swasta. Persaingan dalam penerimaan mahasiswa baru dirasakan semakin ketat. Setiap institusi pendidikan ini berusaha untuk merebut perhatian konsumen, yaitu para calon mahasiswa. Berbagai upaya 
yang dilakukan oleh berbagai perguruan tinggi swasta, antara lain : meningkatkan status akreditasi jurusan yang ada, janji untuk menyalurkan lulusannya ke berbagai perusahaan mitra mereka, dan sebagainya.

Dengan semakin banyaknya perguruan tinggi di Jawa Barat tentunya ini sangat berpengaruh terhadap daya saing dan menentukan posisi sebuah perguruan tinggi. Berdasarkan data Perguruan Tinggi Swasta di Kopertis Wilayah IV Jabar dan Banten.

Tabel 1.1

Data PTS di Jabar Banten

Sumber : Direktori Perguruan Tinggi Kopertis Wilayah IV Jabar dan Banten) Edisi Desember 2014.

\begin{tabular}{|l|l|}
\hline Bentuk PTS & Jumlah PTS \\
\hline Akademik & 142 \\
\hline Institut & 6 \\
\hline Politeknik & 33 \\
\hline Sekolah Tinggi & 246 \\
\hline Universitas & 56 \\
\hline Total & $\mathbf{4 8 3}$ \\
\hline
\end{tabular}

Dari data diatas terlihat Sekolah Tinggi sangat dominan karena tersebar di beberapa daerah yang memaksimalkan potensi daerahnya dengan mengambil segmen pasar yang ingin melanjutkan kuliah namun kendala dari segi biaya atau jauh dari daerah asalnya. Sekolah Tinggi mempunyai segmentasi pasar tersendiri dengan kualifikasi yang tentunya sangat jauh berbeda dengan perguruan tinggi lainnya.

Adanya persaingan tersebut, menyebabkan suatu perguruan tinggi harus dapat mempertahankan diri agar tetap langgeng keberadaannya. Dalam mempertahankan diri ini, salah satu cara yang dapat dilakukan adalah dengan memiliki keunggulan bersaing (competitive advantage), yaitu memiliki keunggulan (di mata mahasiswa dan masyarakat) dibanding perguruan tinggi swasta atau negeri yang lain. Salah satu keunggulan yang ada, yaitu unggul dalam pelayanan jasa pendidikan, agar para calon mahasiswa memiliki minat dan keinginan kuliah di perguruan tinggi ini.

\section{B. PERUMUSAN MASALAH}

Berdasarkan beberapa permasalahan yang telah diungkapkan dalam latar belakang diatas, maka dalam penelitian ini dapat dirumuskan sebagai berikut:

1. Seberapa besar pengaruh kualitas pelayanan terhadap kepuasan mahasiswa Sekolah Tinggi Teknologi Jawa Barat. (STT Jabar).

2. Seberapa besar pengaruh kepuasan mahasiswa terhadap loyalitas mahasiswa Sekolah Tinggi Teknologi Jawa Barat. ( STT Jabar).

\section{TUJUAN PENELITIAN}

Penelitian ini dilakukan dengan tujuan untuk mengetahui dan menganalisis:

1. Besarnya pengaruh hubungan pelayanan terhadap kepuasan mahasiswa Sekolah Tinggi Teknologi Jawa Barat. (STT Jabar).

2. Besarnya pengaruh kepuasan mahasiswa terhadap royalitas mahasiswa Sekolah Tinggi Teknologi Jawa Barat. (STT Jabar).

\section{KAJIAN PUSTAKA}




\section{Loyalitas Pelanggan}

Loyalitas pelanggan secara umum dapat diartikan kesetiaan seseorang atas suatu produk, baik barang maupun jasa tertentu. Istilah loyalitas pelanggan menurut Swastha (1999:73) sebetulnya berasal dari loyalitas merek yang mencerminkan loyalitas pelanggan pada merek tertentu. Pelanggan yang setia pada merek tertentu cenderung terikat pada merek tersebut dan akan membeli produk yang sama lagi sekalipun tersedia banyak alternatif lainnya (Tjiptono, 2007:386).

Menurut Kapferer \& Laurent (dikutip dalam Tjiptono, 2007:386) perilaku pembelian ulang bisa dijabarkan menjadi dua kemungkinan, yakni loyalitas dan inersia. Faktor pembedannya adalah sensitifitas merek yang didefinisikan sebagai sejauh mana nama merek memainkan peran kunci dalam proses pemilihan alternative dalam kategori produk atau jasa tertentu. Sensitifitas merek dipengaruhi oleh persepsi terhadap perbedaan antar merek dan tingkat keterlibatan konsumen dalam kategori merek produk atau jasa. Perilaku pembelian ulang dalam perilaku sensitifitas merek yang kuat dikategorikan sebagai loyalitas, dimana konsumen cenderung membeli atau menggunakan ulang merek yang sama dan menganggap pilihan merek sangat penting baginya. Sebaliknya, pembelian ulang dalam situasi sensitifitas merek yang lemah dikategorikan sebagai inersia, yakni konsumen cenderung membeli ulang merek yang sama, namun ia tidak menganggap nama merek itu penting, karena ia tidak bisa membedakan berbagai merek yang ada dan terlibat secara insentif dalam pemilihan kategori produk.

Signifikasi loyalitas pelanggan sangat terkait dengan kelangsungan perusahaan dan terhadap kuatnya pertumbuhan perusahaan di masa datang, oleh karena itu mempertahankan pelanggan yang ada saat ini lebih penting dibanding strategi agresif seperti memperluas ukuran pasar dengan menggaet konsumen potensial (Lupiyoadi dan Hamdani, 2006:195). Kajian-kajian loyalitas pelanggan dapat dibagi menjadi tiga kategori pendekatan yaitu pendekatan perilaku, pendekatan sikap, dan pendekatan terintegrasi (Oh,1995 dalam Lupiyoadi dan Hamdani,2006:195). Pendekatan perilaku berfokus pada perilaku konsumen purnapembelian dan mengukur loyalitas pelanggan berdasarkan tingkat pembelian (frekuensi dan kemungkinan membeli lagi). Pendekatan sikap menyimpulkan loyalitas pelanggan dari aspek keterlibatan psikologis, favoritisme, dan sense of goodwill pada jasa tertentu. Sementara itu pendekatan terintegrasi mengkombinasikan dua variabel untuk menciptakan sendiri konsep loyalitas pelanggan yaitu kombinasi sikap senang pelanggan dan perilaku pembelian ulang.. Terdapat empat tahapan loyalitas berdasarkan pendekatan attitudinal dan behaviorial yaitu :

1. Loyalitas Kognitif

Konsumen yang mempunyai loyalitas tahap pertama ini menggunakan basis informasi yang secara memaksa menunjuk pada satu merek atas merek lainnya. Jadi loyalitas hanya didasarkan pada kognisi saja. Sebagai contoh, sebuah supermarket secara konsisten selalu menawarkan harga yang lebih murah atau rendah dari pesaing. Informasi ini cukup memaksa konsumen 
untuk selalu berbelanja di supermarket tersebut. Apakah ini merupakan bentuk loyalitas yang kuat. Dalam kenyataan tidak karena pesaing dapat menawarkan informasi (harga produk) yang lebih menarik sehingga konsumen beralih ke pesaing. Jadi pemasar harus mempunyai alasan lebih kuat agar konsumen tetap loyal.

2. Loyalitas Afektif

Loyalitas tahap kedua didasarkan pada aspek afektif konsumen. Sikap merupakan kognisi atau pengharapan pada periode awal pembelian atau masa pra konsumsi dan merupakan fungsi dari sikap sebelumnya plus kepuasan di periode berikutnya atau masa pasca konsumsi. Loyalitas tahap ini jauh lebih sulit dirubah karena loyalitasnya sudah masuk ke dalam benak konsumen sebagai afek dan bukannya sendirian sebagai kognisi yang mudah berubah.

3. Loyalitas Konatif

Konasi menunjukkan suatu niat atau komitmen untuk melakukan sesuatu kearah suatu tujuan tertentu. Maka loyalitas konatif merupakan suatu kondisi loyal yang mencakup komitmen mendalam untuk melakukan pembelian. Jenis komitmen ini sudah melampaui afek. Afek hanya menunjukkan kecenderungan motivasional, sedangkan komitmen untuk melakukan menunjukkan suatu keinginan untuk melaksanakan tindakan. Keinginan untuk membeli ulang atau menjadi loyal itu hanya merupakan tindakan yang terantisipasi tetapi belum terlaksana.

4. Loyalitas Tindakan

Aspek konatif atau niat untuk melakukan mengalami perkembangan, yaitu menjadi perilaku atau kontrol tindakan. Dalam runtutan kontrol tindakan, niat yang diikuti oleh motivasi merupakan kondisi yang mengarah pada kesiapan bertindak dan pada keinginan mengatasi hambatan untuk mencapai tindakan tersebut. Hal ini menunjukkan bagaimana loyalitas itu menjadi kenyataan yaitu pertama sebagai loyalitas kognitif, loyalitas afektif, kemudian loyalitas konatif dan pada akhirnya sebagai loyalitas tindakan atau loyalitas yang ditopang dengan komitmen dan tindakan.

\begin{tabular}{|r|c|c|}
\hline & Kuat & Lemah \\
\hline Kuat & $\begin{array}{c}\text { Loyalitas } \\
\text { Premium }\end{array}$ & $\begin{array}{c}\text { Loyalitas } \\
\text { Tersembunyi }\end{array}$ \\
\hline Lemah & $\begin{array}{c}\text { Loyalitas yang } \\
\text { Lemah }\end{array}$ & $\begin{array}{c}\text { Tanpa } \\
\text { Loyalitas }\end{array}$ \\
\hline
\end{tabular}

Sumber : Griffin, 2005

Gambar 2.1 Empat Jenis Loyalitas

Konsumen yang loyal merek dapat diidentifikasi berdasar pola pembeliannya, seperti runtutan pembelian (tiga atau empat kali pembelian merek yang sama) atau proporsi pembelian (delapan dari sepuluh kali pembelian merek yang sama (Swastha, 1999:86). Menurut Griffin (2005:31) loyalitas dapat didefinisikan berdasarkan perilaku pembeli. Pelanggan yang loyal adalah orang yang memiliki ciri-ciri sebagai berikut :

1. Melakukan pembelian secara berulang secara teratur

2. Membeli antar lini produk dan jasa 
3. Merekomendasikan kepada orang lain

4. Menunjukkan kekebalan terhadap tarikan dari pesaing atau tidak mudah dipengaruhi oleh pesaing untuk pindah. Griffin

(2005:11)

mengemukakan bahwa semakin lama loyalitas seorang pelanggan, semakin besar laba yang dapat diperoleh perusahaan dari satu pelanggan ini. Loyalitas yang meningkat dapat menghemat biaya perusahaan di enam bidang antara lain :

1. Biaya pemasaran menjadi berkurang, karena biaya untuk menarik pelangan baru lebih tinggi daripada biaya mempertahankan pelanggan.

2. Biaya transaksi menjadi lebih rendah, seperti biaya negosiasi kontrak dan pemrosesan pesanan.

3. Biaya perputaran pelanggan menjadi berkurang karena lebih sedikit pelanggan hilang yang harus digantikan.

4. Keberhasilan penjualan silang menjadi meningkat, menyebabkan pangsa pasar yang lebih besar.

5. Pemberitaan dari mulut ke mulut menjadi lebih positif, dengan asumsi para pelanggan yang loyal juga merasa puas.

6. Biaya kegagalan menjadi menurun seperti pengurangan pengerjaan ulang, kalim garansi, biaya pergantian, dan sebagainya.

\section{Kualitas Pelayanan}

\begin{tabular}{l}
\multicolumn{2}{c}{ Pelayanan adalah setiap } \\
tindakan atau kegiatan yang dapat \\
ditawarkan satu pihak kepada pihak \\
lain, yang pada dasarnya tidak \\
berwujud dan tidak mengakibatkan \\
kepemilikan apapun (Laksana,
\end{tabular}

2008:85). Dalam perspektif TQM (Total Quality Management) kualitas dipandang secara lebih luas, yaitu tidak hanya aspek hasil yang ditekankan, tetapi juga meliputi proses, lingkungan dan manusia. Tjiptono dan Chandra (2005:110) menyatakan bahwa Goetsch \& Davis (1994) mendefinisikan kualitas sebagai suatu kondisi dinamis yang berpengaruh dengan produk, jasa, manusia, proses dan lingkungan yang memenuhi atau melebihi harapan.

Menurut Tjiptono dan Chandra (2005:121), Lewis \& Booms mendefinisikan kualitas jasa sebagai ukuran seberapa bagus tigkat layanan yang diberikan mampu sesuai dengan ekspektasi pelanggan. Salah satu faktor yang menentukan keberhasilah suatu perusahaan adalah kemampuan perusahaan memberikan pelayanan yang berkualitas kepada konsumen. Kualitas pelayanan (Service Quality) dibangun atas adanya perbandingan dua faktor utama yaitu persepsi pelanggan atas layanan yang nyata mereka terima (perceived service) dengan layanan yang sesungguhnya diharapkan (Tjiptono dan Chandra,2005:121).

Menurut Lupiyoadi dan Hamdani (2006:182), Parasuraman dkk (1998) mendefinisikan kualitas jasa sebagai seberapa jauh perbedaan antara kenyataan dan harapan pelanggan atas layanan yang mereka terima. Terdapat lima dimensi dalam kualitas pelayanan yang dikemukakan oleh Parasuraman dkk (1998) yaitu :

1. Berwujud (tangible)

Yaitu kemampuan suatu perusahaan dalam menunjukkan eksistensinya kepada pihak eksternal. Penampilan dan kemampuan sarana dan prasarana fisik perusahaan yang dapat diandalkan 
keadaan lingkungan sekitarnya merupakan bukti nyata dari layanan yang diberikan oleh para pemberi jasa. Hal ini meliputi fasilitas fisik (contoh : gedung, gudang dan lain-lain), perlengkapan dan peralatan yang digunakan (teknologi) serta penampilan pegawainya.

2. Keandalan (reliability)

Yaitu kemampuan perusahaan untuk memberikan layanan sesuai dengan dijanjikan secara akurat dan terpercaya. Kinerja harus sesuai dengan harapan pelanggan yang berarti ketepatan waktu, layanan yang sama untuk semua pelanggan tanpa kesalahan, sikap yang simpatik dan dengan akurasi yang tinggi.

3. Ketanggapan (responsiveness) Yaitu suatu kebijakan untuk membantu dan memberikan layanan yang cepat (responsive) dan tepat kepada pelanggan dengan penyampaian informasi yang jelas. Membiarkan konsumen menunggu, persepsi yang negatif dalam kualitas layanan.

4. Jaminan dan kepastian (assurance)

Yaitu pengetahuan, kesopansantunan dan kemampuan para pegawai perusahaan untuk menumbuhkan rasa percaya para pelanggan kepada perusahaan. Hal ini meliputi beberapa komponen anatara lain komunikasi (communication), kredibilitas (credibility), keamanan (security), kompetensi (competence) dan sopan santun (courtesy).

5. Empati (empathy)

Yaitu memberikan perhatian yang tulus dan bersifat individual atau pribadi yang diberikan kepada para pelanggan dengan berupaya memahami keinginan konsumen. Dimana suatu perusahaan diharapkan memilki pengertian dan pengetahuan tentang pelanggan, memahami kebutuhan pelanggan secara spesifik, serta memiliki waktu pengoperasian yang nyaman bagi pelanggan.

\section{Kepuasan Pelanggan}

Kepuasan merupakan salah satu unsur utama dalam upaya untuk mempertahankan konsumen yang telah ada ataupun untuk menarik konsumen yang baru. Lupiyoadi dan Hamdani (2006:196) menuliskan bahwa banyak peneliti melakukan studi untuk memeperlihatkan manfaat dari mempertahankan pelanggan ini, salahsatunya Rosenberg dan Czepiel (1984) yang memperlihatkan bahwa biaya untuk memperoleh pelanggan baru sekitar lima kali lipat dari biaya mempertahankan pelanggan yang ada melalui strategi pemasaran relasional.

Menurut Fandy Tjiptono (2007:349) banyak pakar yang mengemukakan definisi kepuasan konsumen diantaranya adalah Howard dan Sheth (1969) mengungkapkan bahwa kepuasan pelanggan adalah situasi kognitif pembeli berkenaan dengan kesepadanan atau ketidaksepadanan antar hasil yang didapatkan dibandingkan dengan pengorbanan yang dilakukan. Swan, et al. (1980) mendefinisikan kepuasan pelanggan sebagai evaluasi secara sadar atau penilaian kognitif menyangkut apakah kinerja produk relatif bagus atau jelek atau apakah kinerja produk bersangkutan cocok atau tidak cocok dengan tujuan atau 
pemakaiannya, sedangkan Mowen (1995) merumuskan kepuasan pelanggan sebagai sikap keseluruhan terhadap suatu barang atau jasa setelah perolehan dan pemakaiannya (Tjiptono, 2007:349). Dengan kata lain, kepuasan pelanggan merupakan penilaian evaluatif purnabeli yang dihasilkan dari seleksi pembelian spesifik. Secara konseptual, kepuasan pelanggan dapat digambarkan seperti yang ditunjukkan gambar 2.2 sebagai berikut:

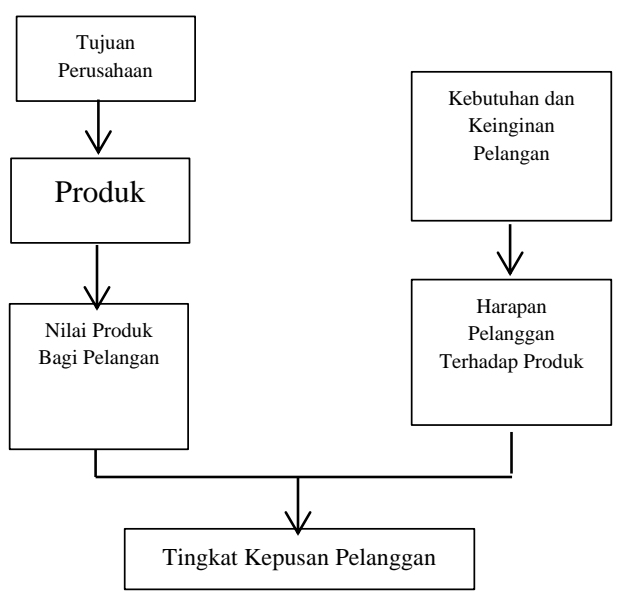

Sumber : Tjiptono, 2004

Gambar 2.2 Konseptual Kepuasan

Tse dan Wilton (dalam Tjiptono
2007:349) menyatakan bahwa
kepuasan atau ketidakpuasan
pelanggan sebagai respon pelanggan
terhadap evaluasi ketidaksesuaian
(disconfirmation)
dipersepsikan antara harapan awal sebelum pembelian dan kinerja aktual produk yang dipersepsikan setelah pemakaian produk. Kotler dan Keller (2008:177), menyatakan bahwa kepuasan adalah perasaan senang atau kecewa seseorang yang muncul setelah membandingan kinerja (atau hasil) produk yang dipikirkan terhadap kinerja (atau hasil) yang diharapan. Dengan kata lain, seseorang merasa puas apabila hasil yang didapat minimal mampu memenuhi harapannya sedangkan seseorang merasa tidak puas apabila hasil yang didapat tidak mampu memenuhi harapannya.

Pada dasarnya kepuasan dan ketidakpuasan pelanggan atas produk atau jasa akan berpengaruh pada pola perilaku selanjutnya. Apabila pelanggan merasa puas, maka dia akan menunjukkan besarnya kemungkinan untuk kembali menggunakan produk atau jasa yang sama. Pelanggan yang puas juga cenderung akan memberikan referensi yang baik terhadap produk atau jasa kepada orang lain (Lupiyoadi dan Hamdani, 2006:194). Tidak demikian dengan pelanggan yang tidak puas. Ketidakpuasan pelanggan bisa menimbulkan sikap negatif terhadap merek maupun produsen atau penyedia jasanya bahkan bisa pula distributornya, berkurangnya kemungkinan pembelian ulang, peralihan merek, dan berbagai macam perilaku komplain (Tjiptono, 2007:352). Realisasi kepuasan pelanggan sangat penting dilakukan perusahaan karena seorang pelanggan yang tidak puas dapat merusak citra perusahaan.

Pengukuran kepuasan pelanggan perlu dilakukan oleh perusahaan untuk mengetahui kinerja perusahaan menurut sudut pandang konsumen. Menurut Fornell (1992) dalam Tjiptono (2007:365), meskipun belum ada konsensus mengenai cara mengukur kepuasan pelanggan, sejumlah studi menunjukan bahwa ada tiga aspek penting yang perlu ditelaah dalam kerangka pengukuran kepuasan pelanggan, yaitu:

1. Kepuasan general atau keseluruhan (overall satisfaction)

2. Konfirmasi harapan (confirmation of expectations), yakni tingkat 
kesesuaian antara kinerja dengan ekspektasi

3. Perbandingan dengan situasi ideal (comparison to ideal), yaitu kinerja produk dibandingkan dengan produk ideal menurut persepsi konsumen

Menurut Andreassen (1998) dalam Natalia (2011:12) beberapa indikator kepuasan konsumen antara lain :

1. Overal Satisfaction, yaitu kepuasan secara keseluruhan konsumen setelah mengkonsumsi produk.

2. Expectation Satisfaction, yaitu harapan kepuasan yang ingin diperoleh konsumen setelah mengkonsumsi produk.

3. Experience Satisfaction, yaitu tingkat kepuasan yang dialami oleh konsumen selama mengkonsumsi produk.

Kotler (2000) dalam Tjiptono (2007:367) menyatakan ada empat metode yang banyak digunakan dalam pengukuran kepuasan pelanggan, yaitu:

1. Sistem keluhan dan saran

Setiap organisasi yang berorientasi pada pelanggan wajib memberikan kesempatan yang seluas-luasnya bagi para pelanggannya untuk menyampaikan saran, kritik, pendapat, dan keluhan mereka.

2. Ghost Shopping

Salah satu metode untuk memperoleh gambaran mengenai kepuasan pelanggan adalah dengan mempekerjakan beberapa orang ghost shoppers untuk berperan sebagai pelanggan potensial jasa perusahaan dan pesaing. Mereka diminta melaporkan berbagai temuan penting berdasarkan pengalamannya mengenai kekuatan dan kelemahan jasa perusahaan dibandingkan para pesaing. Selain itu para ghost shoppers juga dapat mengobservasi cara perusahaan dan pesaingnya melayani permintaan spesifik pelanggan, menjawab pertanyaan pelanggan, dan menangani setiap masalah atau keluhan pelanggan

3. Lost costumer analysis

Perusahaan seyogyanya menghubungi para pelanggan yang telah berhenti membeli atau yang telah beralih pemasok agar dapat memahami mengapa hal itu terjadi dan supaya dapat mengambil perbaikan/ penyempurnaan selanjutnya.

4. Survei kepuasan pelanggan Umumnya sebagian besar penelitian mengenai kepuasan pelanggan menggunakan metode survei, baik via pos, telepon, e-mail, maupun wawancara langsung. Melalui survei, perusahaan akan memperoleh tanggapan dan umpan balik langsung dari pelanggan dan juga memberikan sinyal positif bahwa perusahaan menaruh perhatian terhadap mereka, 2013).

\section{Pengertian Analisis Jalur}

Analisis jalur ialah suatu tehnik untuk menganalisis hubungan sebab akibat yang terjadi pada regresi berganda jika variabel bebasnya mempengaruhi variabel tergantung tidak hanya secara langsung, tetapi juga secara tidak langsung (Robert D. Rutherford 1993 dikutip oleh Sarwono, 2007).

\section{Manfaat Analisis Jalur}


Menurut Saparina (2013), ada beberapa manfaat analisis jalur diantaranya adalah:

1. Sebagai penjelas terhadap fenomena yang dipelajari atau permasalahan yang diteliti.

2. Untuk prediksi nilai variabel endogenous (Y) berdasarkan nilai variabel eksogenous (X).

\section{E. METODE PENELITIAN}

\section{Desain Penelitian}

Penelitian menggunakan metode survei dan analisis kuantitatif. Metode survey ialah metode penelitian yang mengambil sampel dari populasi serta menggunakan kuesioner sebagai alat pengumpul data yang pokok. Alasan menggunakan metode ini karena semua anggota populasi dijadikan sampel, unit analisisnya bersifat individu dan penelitian ini menggunakan pendekatan kuantitatif.

Kegiatan penelitian diarahkan untuk menghimpun data-data yang terdapat di lapangan, kemudian penggambarannya didasarkan pada hasil uji statistik, sehingga dari tahapan tersebut dapat diperoleh makna dan arti.

Secara keseluruhan proses penelitian dapat digambarkan sebagai berikut :

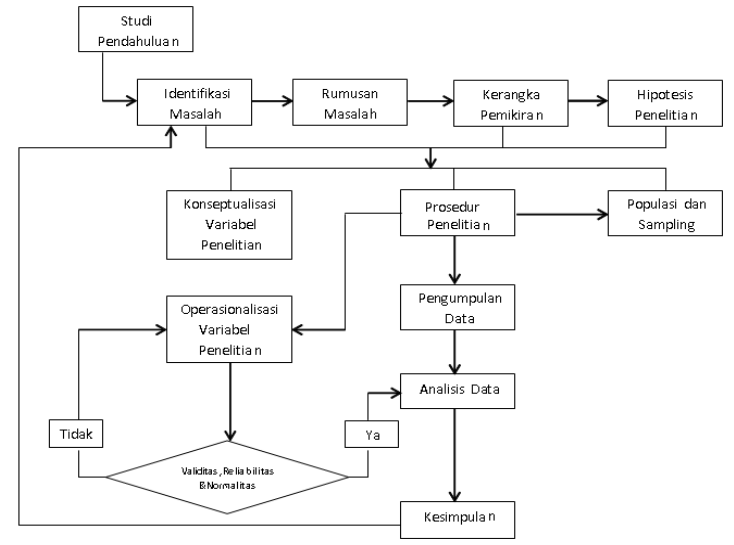

Gambar 3.1 Desain Penelitian

\section{Variabel dan Definisi Operasional}

\section{Variabel}

Variabel dalam penelitian ini ditetapkan variabel sebagai berikut:

1. Kualitas Layanan berfungsi sebagai variabel bebas (Independent variable) yang kemudian diberi notasi X1

2. Kepuasan Mahasiswa berfungsi sebagai variabel antara (Intervening Variable) yang kemudian diberi notasi Y.

3. Loyalitas Mahasiswa berfungsi sebagai variabel terikat (Dependen variabel) yang kemudian diberi notasi $\mathrm{Z}$.

\section{Definisi Operasional Varibel}

Sesuai dengan variabel penelitian yaitu kualitas layanan, kepuasan Mahasiswa dan loyalitas mahasiswa secara operasional dapat didefinisikan pada table 3.2.

Tabel 3.2

Operasional Penelitian

\begin{tabular}{|c|c|c|c|c|}
\hline Variabel & Defenisi & Dimensi & Indikator & Skala \\
\hline $\begin{array}{l}\text { Kualitas } \\
\text { Pelayanan } \\
\text { (X1) }\end{array}$ & $\begin{array}{l}\text { Kualitas } \\
\text { pelayanan } \\
\text { adalah tingkat } \\
\text { keunggulan } \\
\text { yang }\end{array}$ & $\begin{array}{l}\text { 1.Berwujd } \\
\qquad(\text { tangible })\end{array}$ & $\begin{array}{ll}\text { 1. } & \text { Kondisi gedung } \\
\text { 2. } & \text { Letak gedung } \\
\text { 3. } & \text { Penampilan petugas } \\
\text { 4. } & \text { Pengaturan tata ruang }\end{array}$ & $\begin{array}{l}\text { Skala } \\
\text { Likert } \\
1-5\end{array}$ \\
\hline
\end{tabular}




\begin{tabular}{|c|c|c|c|c|}
\hline Variabel & Defenisi & Dimensi & Indikator & Skala \\
\hline & $\begin{array}{l}\text { diharapkan } \\
\text { dan } \\
\text { pengendalian } \\
\text { atas tingkat } \\
\text { keunggulan }\end{array}$ & $\begin{array}{l}\text { 2. Empati } \\
\text { (empathy) }\end{array}$ & $\begin{array}{ll}\text { 1. } & \text { Perhatian } \\
\text { 2. } & \text { Sikap } \\
\text { 3. } & \text { Kemampuan } \\
\text { 4. } & \text { Kesopanan }\end{array}$ & $\begin{array}{l}\text { Skala } \\
\text { Likert } \\
1-5\end{array}$ \\
\hline & $\begin{array}{l}\text { tersebut untuk } \\
\text { memenuhi } \\
\text { keinginan } \\
\text { pelanggan }\end{array}$ & $\begin{array}{l}\text { 3. Kehandalan } \\
\text { (reliability) }\end{array}$ & $\begin{array}{ll}\text { 1. } & \text { Kecermatan } \\
\text { 2. } & \text { Ketrampilan } \\
\text { 3. } & \text { Ketepatan pelayanan } \\
\text { 4. } & \text { Kesiapan }\end{array}$ & $\begin{array}{l}\text { Skala } \\
\text { Likert } \\
1-5\end{array}$ \\
\hline & & $\begin{array}{l}\text { 4. Responsive } \\
\text { (responsiveness) }\end{array}$ & $\begin{array}{l}\text { 1. } \quad \text { Pemberian informasi } \\
\text { 2. Kecepatan pelayanan } \\
\text { 3. Ketanggapan dalam } \\
\text { melayani }\end{array}$ & $\begin{array}{l}\text { Skala } \\
\text { Likert } \\
1-5\end{array}$ \\
\hline & & $\begin{array}{l}\text { 5. Jaminan } \\
\text { (assurance) }\end{array}$ & $\begin{array}{ll}\text { 1. } & \text { Ketepatan waktu. } \\
\text { 2. } & \text { Prestasi } \\
\text { 3. } & \text { Reputasi }\end{array}$ & $\begin{array}{l}\text { Skala } \\
\text { Likert } \\
1-5\end{array}$ \\
\hline \multirow{3}{*}{$\begin{array}{l}\text { Kepuasan } \\
\text { (Y1) }\end{array}$} & $\begin{array}{l}\text { Kepuasan } \\
\text { konsumen } \\
\text { adalah tingkat } \\
\text { perasaan } \\
\text { seseorang } \\
\text { setelah } \\
\text { membandingkan } \\
\text { antara kinerja } \\
\text { yang dirasakan } \\
\text { dengan harapan }\end{array}$ & $\begin{array}{l}\text { 1.Kinerja dan } \\
\text { Keistimewaan } \\
\text { Jasa }\end{array}$ & $\begin{array}{l}\text { 1. Kepercayaan } \\
\text { kelebihan jasa } \\
\text { 2. Manfaat } \\
\text { pengalaman penggunaan jasa }\end{array}$ & $\begin{array}{l}\text { Skala } \\
\text { Likert } \\
1-5\end{array}$ \\
\hline & & $\begin{array}{l}\text { 2.Kepuasan } \\
\text { Layanan Secara } \\
\text { Umum }\end{array}$ & $\begin{array}{l}\text { 1. Kepuasan layanan } \\
\text { secara umum } \\
2 . \quad \text { Kecepatan pelayanan } \\
\text { bagi pelanggan. } \\
\text { 3. Kemudahan pelayanan }\end{array}$ & $\begin{array}{l}\text { Skala } \\
\text { Likert } \\
1-5\end{array}$ \\
\hline & & $\begin{array}{l}\text { 3.Perbandingan } \\
\text { antara harapan } \\
\text { dengan } \\
\text { kenyataan }\end{array}$ & $\begin{array}{lc}\text { 1. } & \text { Jasa } \\
\text { manfaat sesuai dengan harapan } \\
\text { 2. } & \text { Manfaat sesuai dengan } \\
\text { harga } & \\
\text { 3. } & \text { Kepastian komitmen }\end{array}$ & $\begin{array}{l}\text { Skala } \\
\text { Likert } \\
1-5\end{array}$ \\
\hline
\end{tabular}




\begin{tabular}{|c|c|c|c|c|}
\hline Variabel & Defenisi & Dimensi & Indikator & Skala \\
\hline \multirow{5}{*}{$\begin{array}{l}\text { Loyalitas } \\
\text { (Y2) }\end{array}$} & \multirow{5}{*}{$\begin{array}{l}\text { Loyalitas adalah } \\
\text { perilaku } \\
\text { pembelian yang } \\
\text { dapat diartikan } \\
\text { sebagai pola } \\
\text { pembelian yang } \\
\text { teratur dan } \\
\text { dalam waktu } \\
\text { yang lama }\end{array}$} & $\begin{array}{l}\text { 1.Frekuensi } \\
\text { kunjungan }\end{array}$ & $\begin{array}{lcr}\text { 1. } & \text { Sering datang ke STT } \\
\text { Jabar } & & \\
2 . & \text { Sering } & \text { menggunakan } \\
\text { jasa } & \text { STT Jabar } & \end{array}$ & $\begin{array}{l}\text { Skala } \\
\text { Likert } \\
1-5\end{array}$ \\
\hline & & $\begin{array}{l}\text { 2. Tidak mudah } \\
\text { beralih }\end{array}$ & $\begin{array}{ll}\text { 1. Tidak } & \text { mudah } \\
\text { terpengaruh } & \\
2 . \quad \text { Konsisten } & \text { dalam } \\
\text { memilih STT Jabar } & \end{array}$ & $\begin{array}{l}\text { Skala } \\
\text { Likert } \\
1-5\end{array}$ \\
\hline & & $\begin{array}{l}\text { 3. Melakukan } \\
\text { promosi dari } \\
\text { mulut ke mulut }\end{array}$ & 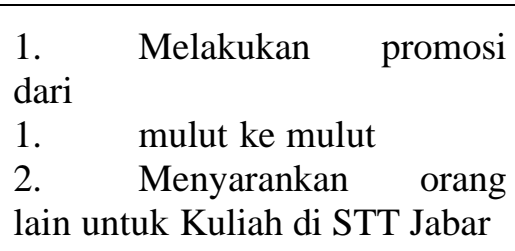 & $\begin{array}{l}\text { Skala } \\
\text { Likert } \\
1-5\end{array}$ \\
\hline & & $\begin{array}{l}4 . \\
\text { Menyampaikan } \\
\text { keluhan }\end{array}$ & $\begin{array}{l}\text { 1. Menyampaikan } \\
\text { keluhan } \\
\text { 2. Menyampaikan } \\
\text { informasi } \\
\text { 3. Menyampaikan ide } \\
\text { 4. Menyampaikan saran }\end{array}$ & $\begin{array}{l}\text { Skala } \\
\text { Likert } \\
1-5\end{array}$ \\
\hline & & $\begin{array}{l}\text { 5. Melakukan } \\
\text { pembelaan }\end{array}$ & $\begin{array}{l}\text { 1. Menyampaikan hal } \\
\text { positif kepada orang lain } \\
\text { 2. } \quad \text { Melakukan pembelaan }\end{array}$ & $\begin{array}{l}\text { Skala } \\
\text { Likert } \\
1 \\
5\end{array}$ \\
\hline
\end{tabular}

\section{F. HASIL PENELITIAN DAN PEMBAHASAN}

Uji Kualitas Data

Uji Reliabilitas dan Validitas

Tabel 4.7

Reliabilitas dan Validitas

\section{Kualitas Layanan}

\section{Item-Total Statistics}

\begin{tabular}{|c|c|c|c|c|}
\hline & $\begin{array}{c}\text { Scale } \\
\text { Mean if } \\
\text { Item } \\
\text { Deleted }\end{array}$ & $\begin{array}{c}\text { Scale } \\
\text { Variance if } \\
\text { Item } \\
\text { Deleted }\end{array}$ & $\begin{array}{c}\text { Corrected } \\
\text { Item-Total } \\
\text { Correlatio } \\
\text { Cronbach's }\end{array}$ & $\begin{array}{c}\text { Alpha if } \\
\text { Item } \\
\text { Deleted }\end{array}$ \\
\hline x1 & 95.7391 & 346.330 & $\mathbf{. 5 8 4}$ & .966 \\
\hline x2 & 95.6087 & 341.977 & $\mathbf{. 7 2 5}$ & .965 \\
\hline
\end{tabular}

\begin{tabular}{|c|c|c|c|c|}
\hline $\mathrm{x} 3$ & 95.3043 & 344.394 & $\mathbf{. 7 0 3}$ & .965 \\
\hline $\mathrm{x} 4$ & 95.4565 & 330.654 & $\mathbf{. 8 3 5}$ & .964 \\
\hline $\mathrm{x} 5$ & 95.5000 & 332.744 & $\mathbf{. 7 6 1}$ & .964 \\
\hline $\mathrm{x} 6$ & 95.1087 & 345.477 & $\mathbf{. 6 7 3}$ & .965 \\
\hline $\mathrm{x} 7$ & 95.1739 & 340.458 & $\mathbf{. 6 7 1}$ & .965 \\
\hline $\mathrm{x} 8$ & 94.9783 & 345.044 & $\mathbf{. 7 3 4}$ & .965 \\
\hline $\mathrm{x} 9$ & 95.1087 & 342.321 & $\mathbf{. 6 6 9}$ & .965 \\
\hline $\mathrm{x} 10$ & 95.1957 & 336.739 & $\mathbf{. 8 1 1}$ & .964 \\
\hline $\mathrm{x} 11$ & 94.8696 & 352.205 & $\mathbf{. 6 2 7}$ & .965 \\
\hline $\mathrm{x} 12$ & 95.1087 & 333.432 & $\mathbf{. 8 7 9}$ & .963 \\
\hline $\mathrm{x} 13$ & 95.1304 & 346.916 & $\mathbf{. 6 0 9}$ & .965 \\
\hline $\mathrm{x} 14$ & 95.4565 & 336.654 & $\mathbf{. 7 1 0}$ & .965 \\
\hline $\mathrm{x} 15$ & 94.9130 & 351.770 & $\mathbf{. 5 6 8}$ & .966 \\
\hline $\mathrm{x} 16$ & 95.0652 & 343.485 & $\mathbf{. 7 5 0}$ & .964 \\
\hline $\mathrm{x} 17$ & 94.9565 & 343.331 & $\mathbf{. 6 9 0}$ & .965 \\
\hline $\mathrm{x} 18$ & 95.2826 & 332.029 & $\mathbf{. 8 7 3}$ & .963 \\
\hline $\mathrm{x} 19$ & 94.8696 & 347.849 & $\mathbf{. 7 8 1}$ & .964 \\
\hline $\mathrm{x} 20$ & 95.1957 & 339.939 & $\mathbf{. 8 1 1}$ & .964 \\
\hline
\end{tabular}




\begin{tabular}{|c|c|c|c|c|}
\hline x21 & 94.9565 & 339.243 & $\mathbf{. 8 3 7}$ & .964 \\
\hline x22 & 95.1304 & 344.738 & $\mathbf{. 7 3 9}$ & .964 \\
\hline x23 & 95.3478 & 343.921 & $\mathbf{. 7 0 5}$ & .965 \\
\hline x24 & 95.1304 & 349.938 & $\mathbf{. 6 6 1}$ & .965 \\
\hline x25 & 95.0652 & 351.929 & $\mathbf{. 5 8 9}$ & .966 \\
\hline
\end{tabular}

\section{Kepuasan}

\section{Item-Total Statistics}

\begin{tabular}{|l|c|c|c|l|}
\hline & $\begin{array}{c}\text { Scale } \\
\text { Mean if } \\
\text { Item } \\
\text { Deleted }\end{array}$ & $\begin{array}{c}\text { Scale } \\
\text { Variance } \\
\text { if Item } \\
\text { Deleted }\end{array}$ & $\begin{array}{c}\text { Corrected } \\
\text { Item- } \\
\text { Total } \\
\text { Correlati } \\
\text { on }\end{array}$ & $\begin{array}{c}\text { Cronbach } \\
\text { 's Alpha } \\
\text { if Item } \\
\text { Deleted }\end{array}$ \\
\hline Y1 & 47.3696 & 135.083 & $\mathbf{. 6 5 7}$ & .960 \\
Y2 & 47.0435 & 133.731 & $\mathbf{8 3 0}$ & .956 \\
Y3 & 47.1522 & 132.487 & $\mathbf{. 7 6 5}$ & .957 \\
Y4 & 47.3043 & 127.150 & $\mathbf{. 8 4 6}$ & .955 \\
Y5 & 47.1304 & 129.494 & $\mathbf{. 8 5 9}$ & .955 \\
Y6 & 47.0217 & 133.311 & $\mathbf{. 8 3 5}$ & .956 \\
Y7 & 47.0870 & 132.659 & $\mathbf{. 8 3 2}$ & .956 \\
Y8 & 47.1304 & 130.560 & $\mathbf{8 3 1}$ & .956 \\
Y9 & 47.0870 & 130.437 & $\mathbf{8 4 1}$ & .955 \\
Y10 & 47.1739 & 133.836 & $\mathbf{. 7 5 3}$ & .957 \\
Y11 & 46.8913 & 130.543 & $\mathbf{8 6 4}$ & .955 \\
Y12 & 47.0870 & 133.192 & $\mathbf{. 7 9 1}$ & .957 \\
Y13 & 47.3478 & 136.454 & $\mathbf{. 7 0 2}$ & .959 \\
Y14 & 47.3478 & 144.676 & $\mathbf{. 4 6 0}$ & .963 \\
\hline
\end{tabular}

\section{Loyalitas}

\section{Item-Total Statistics}

\begin{tabular}{|c|c|c|c|c|}
\hline & $\begin{array}{l}\text { Scale } \\
\text { Mean if } \\
\text { Item } \\
\text { Deleted }\end{array}$ & \begin{tabular}{|l} 
Scale \\
Varianc \\
e if \\
Item \\
Deleted
\end{tabular} & \begin{tabular}{|l} 
Correct \\
ed Item- \\
Total \\
Correlat \\
ion
\end{tabular} & $\begin{array}{l}\text { Cronbac } \\
\text { h's } \\
\text { Alpha if } \\
\text { Item } \\
\text { Deleted }\end{array}$ \\
\hline Y1 & 47.3696 & 135.083 & .657 & .960 \\
\hline Y2 & 47.0435 & 133.731 & .830 & .956 \\
\hline Y3 & 47.1522 & 132.487 & .765 & .957 \\
\hline Y4 & 47.3043 & 127.150 & .846 & .955 \\
\hline Y5 & 47.1304 & 129.494 & .859 & 955 \\
\hline Y6 & 47.0217 & 133.311 & .835 & .956 \\
\hline Y7 & 47.0870 & 132.659 & .832 & .956 \\
\hline Y8 & 47.1304 & 130.560 & .831 & .956 \\
\hline Y9 & 47.0870 & 130.437 & .841 & .955 \\
\hline Y10 & 47.1739 & 133.836 & .753 & .957 \\
\hline Y11 & 46.8913 & 130.543 & .864 & .955 \\
\hline Y12 & 47.0870 & 133.192 & .791 & .957 \\
\hline
\end{tabular}

\begin{tabular}{|l|l|l|l|l|}
\hline & & Scale & Correct & Cronbac \\
& Scale & Varianc & ed Item- & h's \\
& Mean if & e if & Total & Alpha if \\
& Item & Item & Correlat & Item \\
& Deleted & Deleted & ion & Deleted \\
\hline Y13 & 47.3478 & 136.454 & $\mathbf{7 0 2}$ & .959 \\
Y14 & 47.3478 & 144.676 & $\mathbf{4 6 0}$ & .963 \\
\hline
\end{tabular}

Pengujian tingkat validitas tiap item dipergunakan analisis item, artinya mengkorelasikan skor tiap item dengan skor total yang merupakan jumlah tiap skor item. Menurut Sugiyono $(2003 ; 178)$, item yang mempunyai korelasi positif dengan skor total serta korelasi yang tinggi, menunjukkan bahwa item tersebut mempunyai validitas yang tinggi pula. Persyaratan minimum agar dapat dianggap valid apabila $r=0,3$. Sehingga apabila korelasi antar item dengan skor total kurang dari 0,3 maka item dalam instrument tersebut dinyatakan tidak valid.

Dari hasil Rekapitulasi Uji Validasi dan Reliabilitas Jawaban Responden olah data menggunakan Sofware SPSS diperoleh hasil validitas keseluruhan variabel adalah valid karena berada diatas angka $\mathrm{r}$ hitung yaitu paling kecil 0,56 berarti diatas 0,3 . Hasil pengujian secara lengkap dapat dilihat pada lampiran.

Tabel 4.6

Kriteria Skor Tiap Variabel

\begin{tabular}{|l|l|l|}
\hline Variabel & Rata-rata & Kriteria \\
\hline $\begin{array}{l}\text { Kualitas } \\
\text { layanan }\end{array}$ & 3,9436 & Baik/tinggi \\
\hline $\begin{array}{l}\text { Kepuasan } \\
\text { Mahasiswa }\end{array}$ & 3,6171 & Baik/tinggi \\
\hline $\begin{array}{l}\text { Loyalitas } \\
\text { mahasiswa }\end{array}$ & 3,4481 & Baik/tinggi \\
\hline
\end{tabular}

Berdasarkan tabel di atas, terlihat bahwa semua variabel 
dikategorikan Baik/tinggi

\section{Analisis Varifikatif}

\section{Hubungan Antar Variabel}

Tabel dibawah ini menampilkan hasil pengolahan data mengenai keterkaitan antar variabel yang diteliti, seperti disajikan sebagai berikut :

Tabel 5.1

Korelasi Antar Variabel

\section{Correlations}

\begin{tabular}{|ll|l|l|l|}
\hline & & X1 & Y2 & Y1 \\
\hline Pearson & X1 & 1.000 & .368 & .349 \\
& Y2 & .368 & 1.000 & .083 \\
& Y1 & .349 & .083 & 1.000 \\
\hline Sig. (1-tailed) & X1 &. & .006 & .009 \\
& Y2 & .006 &. & .291 \\
& Y1 & .009 & .291 & \\
& X1 & 46 & 46 & 46 \\
& Y2 & 46 & 46 & 46 \\
& Y1 & 46 & 46 & 46 \\
\hline
\end{tabular}

Adapun kriteria penilaian korelasi menurut sugiono $(2003 ; 216)$

Tabel 5.2

Kriteria Penilaian Korelasi

\begin{tabular}{|l|l|}
\hline $\begin{array}{l}\text { Interval } \\
\text { Koefisien }\end{array}$ & $\begin{array}{l}\text { Tingkat } \\
\text { hubungan }\end{array}$ \\
\hline $0,00-0,199$ & Sangat Rendah \\
\hline $0,20-0,399$ & Rendah \\
\hline $0,40-0,599$ & Sedang \\
\hline
\end{tabular}

\begin{tabular}{|l|l|}
\hline $0,60-0,799$ & Kuat \\
\hline $0,80-1,000$ & Sangat Kuat \\
\hline
\end{tabular}

Perhitungan Korelasi dilakukan dengan menggunakan program SPSS.

Dari hasil uji korelasi tersebut menunjukkan semua variabel berkorelasi yaitu :

1. Variabel Layanan Kualiatas (X1) terhadap variabel Kepuasan Mahasiswa (Y1) yaitu 0,349 ini memperlihatkan rendah menurut sugiono (2003; 216)

2. Variabel Kepuasan Mahasiswa (Y1) terhadap variabel Loyalitas Mahasiswa (Y2) yaitu 0,083 ini memperlihatkan sangat rendah menurut sugiono $(2003 ; 216)$

3. Variabel Loyalitas Mahasiswa (Y2) terhadap variabel Layanan Kualiatas (X1) yaitu 0,368 ini memperlihatkan rendah menurut sugiono $(2003 ; 216)$

\section{Analisis Jalur}

Hasil pengujian jalur (path analysis) melalui software SPSS diperoleh hasil sebagi berikut :

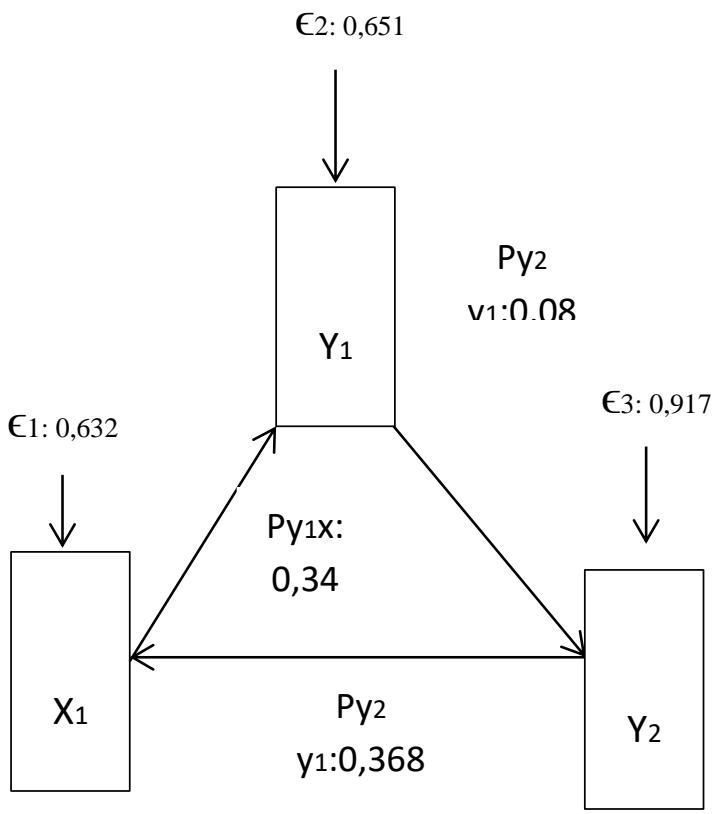


Gambar 5.1 hasil pengujian jalur

Melalui gambar 5.1 di atas, dapat diformulasikan hasil pengujian melalui tabel sebagai berikut :

Tabel 5.3

Hasil perhitungan jalur

\begin{tabular}{|l|l|}
\hline Variabel & Koefisien Jalur \\
\hline $\begin{array}{l}\text { Kualitas layanan } \\
(\mathrm{X} 1)\end{array}$ & 0,349 \\
\hline $\begin{array}{l}\text { Kepuasan } \\
\text { Mahasiswa (Y1) }\end{array}$ & 0,083 \\
\hline $\begin{array}{l}\text { Loyalitas } \\
\text { Mahasiswa (Y2) }\end{array}$ & 0,368 \\
\hline
\end{tabular}

Sumber : Hasil perhitungan Statistik

Nilai Koefisien Jalur

Uji Hipotesis H1

Tabel 5.4

Nilai Koefisien Jalur H1

\begin{tabular}{|c|c|c|c|c|c|}
\hline \multirow[t]{2}{*}{ Model } & $\begin{array}{l}\text { Unstai } \\
\text { Coeff }\end{array}$ & $\begin{array}{l}\text { ndardiz } \\
\text { d } \\
\text { icients }\end{array}$ & $\mid \begin{array}{c}\text { Standar } \\
\text { dized } \\
\text { Coeffic } \\
\text { ients }\end{array}$ & \multirow[t]{2}{*}{$\mathrm{t}$} & \multirow[t]{2}{*}{ Sig } \\
\hline & B & $\begin{array}{l}\text { Std. } \\
\text { Error }\end{array}$ & Beta & & \\
\hline $\begin{array}{ll}1 & \text { (Cons } \\
& \tan t)\end{array}$ & 28.506 & 9.186 & & $\begin{array}{l}3.10 \\
3\end{array}$ & .003 \\
\hline $\mathrm{X} 1$ & .225 & .091 & .349 & $\begin{array}{l}2.47 \\
0\end{array}$ & .017 \\
\hline
\end{tabular}

Signifikasi 0,017 lebih kecil dari signifikasi 0,05 sebesar t hitung 2,470 yang menyatakan bahwa ho ditolak yang berarti terdapat pengaruh kualiats layanan terhadap kepuasan.

\section{Uji Hipotesis H2}

\section{Tabel 5.5}

Nilai Koefisien Jalur H2

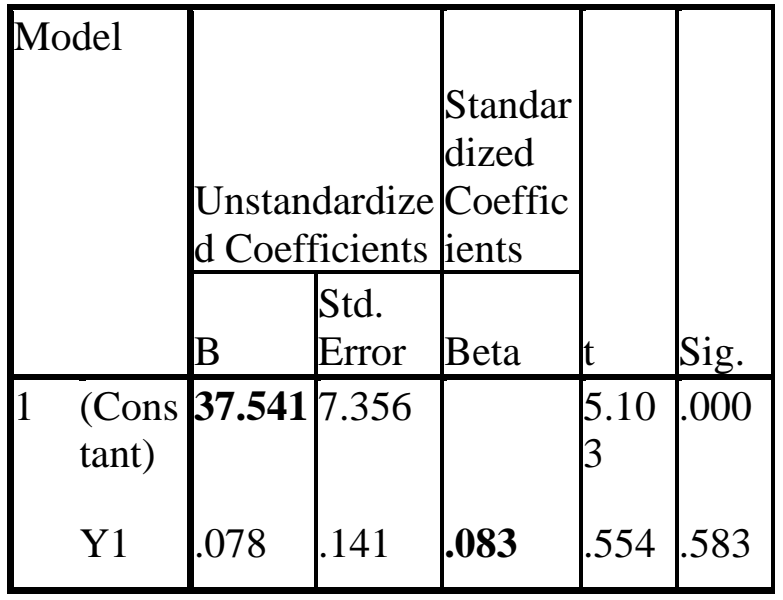

Signifikasi 0,583 lebih lebih besar dari signifikasi 0,05 sebesar $\mathrm{t}$ hitung 0,554 yang menyatakan bahwa ho di terima yang berarti tidak terdapat pengaruh antara kepuasan terhadap royalitas

Tabel diatas menggambarkan persamaan jalur. Dengan memperhatikan tabel diatsa dapat diperoleh persamaan jalur, yaitu :

1. Persamaan Struktural $1(\mathrm{H} 1)$ $\mathrm{X}=0,349 \mathrm{Y} 1+28,506+\epsilon 1$ Maka dari hasil persamaan 1 dapat dianalisis bahwa jika kualitas pelayanan (x) meningkat $1 \%$ saja maka akan mempengaruhi kepuasan mahasiswa (y1) sebanyak $28,506 \%$.

2. Persamaan Struktural $2(\mathrm{H} 2)$ $\mathrm{Y} 1=0,996 \mathrm{Y} 2+37,541+\epsilon 2$ Maka dari hasil persamaan 2 dapat dianalisis bahwa jika kepuasan mahasiswa (y1) meningkat $1 \%$ saja maka akan mempengaruhi loyalitas mahasiswa (y2) sebanyak $37,541 \%$.

\section{Koefisien Determinasi}

Koefisien Determinasi (square Multiple Corelation) merupakan koefisien yang digunakan untuk mengetahui besarnya konstribusi variabel independen terhadap 
perubahan variabel dependen.

Tabel 5.7

Koefisien Determinasi X1-Y1

\begin{tabular}{|l|c|c|c|c|}
\hline Model & $\mathrm{R}$ & $\begin{array}{c}\mathrm{R} \\
\text { Square }\end{array}$ & $\begin{array}{c}\text { Adjusted } \\
\mathrm{R} \\
\text { Square }\end{array}$ & $\begin{array}{c}\text { Std. } \\
\text { Error of } \\
\text { the } \\
\text { Estimate }\end{array}$ \\
\hline 1 & $.349^{\mathrm{a}}$ & $\mathbf{0 . 1 2 2}$ & $\mathbf{0 . 1 0 2}$ & 11.75771 \\
\hline
\end{tabular}

Artinya : 0,102 kualitas layanan

(X1) mempengaruhi variabel kepuasan mahasiswa (Y1) sebesar 0,122 sedangkan sisanya dipengaruhi oleh variabel lain $1-0,122 \quad(0,878)$ yaitu variabel yang tidak diteliti.

Tabel 5.8

Koefisien Determinasi Y1-Y2 Model Summary

\begin{tabular}{|c|c|c|c|c|}
\hline Model & $\mathrm{R}$ & $\begin{array}{c}\mathrm{R} \\
\text { Square }\end{array}$ & $\begin{array}{c}\text { Adjusted } \\
\mathrm{R} \\
\text { Square }\end{array}$ & $\begin{array}{c}\text { Std. } \\
\text { Error of } \\
\text { the } \\
\text { Estimate }\end{array}$ \\
\hline 1 & .083 & .007 & -.016 & 11.71770 \\
\hline
\end{tabular}

Artinya : 0,16 Kepuasan mahasiswa (Y1) mempengaruhi variabel loyalitas mahasiswa (Y2) sebesar 0,007 sedangkan sisanya dipengaruhi oleh variabel lain $1-0,007 \quad(0,993)$ yaitu variabel yang tidak diteliti.

\section{G. KESIMPULAN DAN SARAN}

Kesimpulan

Pengaruh Kualitas Layanan terhadap Kepuasan Mahasiswa Sekolah Tinggi Teknologi Jawa Barat.

1. Dari hasil pengolahan data dan analisis tentang pengaruh atar variabel Layanan Kualiatas (X1) terhadap variabel Kepuasan Mahasiswa (Y1) yaitu sebesar 0,349 ini memperlihatkan rendah menurut sugiono $(2003 ; 216)$.
2. Dengan terbuktinya hipotesis (H1) yang diajukan dalam penelitian ini, signifikasi 0,017 lebih kecil dari signifikasi 0,05 sebesar t hitung 2,470 yang menyatakan bahwa ho ditolak yang berarti terdapat pengaruh kualiats layanan terhadap kepuasan maka kualitas pelayanan berpengaruh pada kepuasan mahasiswa.

3. Dari hasil perhitungan Koefisien Determinasi (square Multiple Corelation) merupakan koefisien yang digunakan untuk mengetahui besarnya konstribusi variabel independen terhadap perubahan variabel dependen yaitu sebesar 0,102 artinya Kualitas Layanan (X1) mempengaruhi variabel Kepuasan Mahasiswa (Y1) sebesar $\quad 0,122 \quad$ sedangkan sisanya dipengaruhi oleh variabel lain $1-0,122 \quad(0,878)$ yaitu variabel yang tidak diteliti yang mempengaruhi kepuasan mahasiswa.

\section{Pengaruh Kepuasan Mahasiswa terhadap Loyalitas Mahasiswa Sekolah Tinggi Teknologi Jawa Barat.}

1. Dari hasil pengolahan data dan analisis tentang pengaruh atar variabel Kepuasan Mahasiswa (Y1) terhadap variabel Loyalitas Mahasiswa (Y2) yaitu 0,083 ini memperlihatkan sangat rendah menurut sugiono $(2003 ; 216)$

2. Dengan terbuktinya hipotesis (H2) yang diajukan dalam penelitian ini, signifikasi 0,583 lebih lebih besar dari signifikasi 0,05 sebesar t hitung 0,554 yang menyatakan bahwa ho di terima yang berarti tidak terdapat pengaruh antara kepuasan terhadap royalitas maka 
kepuasan belum tentu berpengaruh pada loayalias mahasiswa.

3. Dari hsil perhitungan Koefisien Determinasi (square Multiple Corelation) merupakan koefisien yang digunakan untuk mengetahui besarnya konstribusi variabel independen terhadap perubahan variabel dependen yaitu sebesar 0,16 artinya Kepuasan Mahasiswa (Y1) mempengaruhi variabel loyalitas mahasiswa (Y2) sebesar $\quad 0,007 \quad$ sedangkan sisanya dipengaruhi oleh variabel lain $1-0,007 \quad(0,993)$ yaitu variabel yang tidak diteliti yang mempengaruhi loyalitas mahasiswa.

\section{Saran}

Berdasarkan pada beberapa kesimpulan di atas, dapat dikemukakan beberapa saran sebagai berikut :

1. Dalam langkah untuk meningkatkan kualitas pelayanan terhadap mahasiswa Sekolah Tinggi Teknologi Jawa Barat harus memperhatikan lagi tentang service hotline dengan adanya ini berarti harus 24 jam layanan ini hidup tanpa kecuali.

2. Dalam langkah untuk meningkatkan kepuasan mahasiswa dari jarak kampus ke sekolah itu cukup jauh maka Sekolah Tinggi Teknologi Jawa Barat harus menyedikan alat transportasi gratis untuk mahasiswa.

3. Sekolah Tinggi Teknologi Jawa Barat harus meningkatkan pelayanan atau kualitas layanan bagi mahasiswa baik dari saran kuliah, sarana praktikum, dosen dan petugas administrasi untuk memuaskan mahasiswa sehingga mahasiswa atau alumni merasa dipuaskan oleh Sekolah Tinggi Teknologi Jawa Barat sehingga mahasiswa merasa puas sehingga dapat memberikan informasiinformasi positif kepada masyarakat luas.

\section{DAFTAR PUSTAKA}

Aisah. 2014 Pengaruh Fasilitas, Kualitas Layanan Terhadap Kepuasan Pasen Serta Implikasinya Pada Loyalitas Pasien. Tesis. Bandung.

Hardiansyah. 2011. Kualitas Pelayanan Publik. Yogyakarta.: Gava Media.

Jasfar F. 2009. Manajemen Jasa. Bogor : Ghalia Indonesia

Kirom B. 2015. Mengukur Kinerja Pelayanan dan Kepuasan Konsumen.Bandung ; Pustaka Reka Cipta.

Kotler, P. dan Keller, K.L. 2007. Manajemen Pemasaran. Jilid 1 dan 2. Jakarta: PT Indeks.

Mukarom Z. 2015. Manajemen Pelayanan Publik. Bandung: Pustaka setia

Moeheriono.2012. Pengukuran Kinerja Berbasis Kopetensi. Jakarta; Raja Grafindo Persada

Mulyana.A. 2014 . Pengaruh FaktorFaktor Kualitas Pelayanan Terhadap Kepuasan Mahasiswa. Tesis. Bandung.

Riduwan, 2010.Cara Menggunakan dan memakai Analisis Jalur (Path Analysis). Bandung: Alfabeta.

Pardede R. 2014. Analisis Jalur (Teori dan Aplikasi dalam Riset Bisnis). Jakarta: Rineka Cipta.

Sandjojo N. 2011 Metode Analisis Jalur dan Aplikasinya. Jakarta ; Pustaka Sinar Harapan. 
Suprato. 2001. Mengukur Tingkat Kepuasan Pelangan.Jakarta ; Rineka Cipta.

Suparto J. 2001 Statistik Teori dan Aplikasi. Jakatra ; Erlanga.

Susanto.Aji. 2014. Analisis Pengaruh Kualitas Pelayana Harga Fasilitas Terhadap Kepuasan Mahasiswa. Jurnal. 